\title{
Multiple Determinants of Externalizing Behavior in 5-Year-Olds: A Longitudinal Model
}

\author{
Sanny Smeekens • J. Marianne Riksen-Walraven • \\ Hedwig J. A. van Bakel
}

Published online: 23 January 2007

(C) Springer Science+Business Media, LLC 2007

\begin{abstract}
In a community sample of 116 children, assessments of parent-child interaction, parent-child attachment, and various parental, child, and contextual characteristics at 15 and 28 months and at age 5 were used to predict externalizing behavior at age 5 , as rated by parents and teachers. Hierarchical multiple regression analysis and path analysis yielded a significant longitudinal model for the prediction of age 5 externalizing behavior, with independent contributions from the following predictors: child sex, partner support reported by the caregiver, disorganized infant-parent attachment at 15 months, child anger proneness at 28 months, and one of the two parent-child interaction factors observed at 28 months, namely negative parent-child interactions. The other, i.e., a lack of effective guidance, predicted externalizing problems only in highly anger-prone children. Furthermore, mediated pathways of influence were found for the parent-child interaction at 15 months (via disorganized attachment) and parental ego-resiliency (via negative parentchild interaction at 28 months).
\end{abstract}

Keywords Externalizing behavior - Early predictors . Longitudinal model $\cdot$ Disorganized attachment .

Parent-child interaction

\section{S. Smeekens}

Department of Developmental Psychology,

Behavioural Science Institute, Radboud University

Nijmegen, The Netherlands

\section{J. M. Riksen-Walraven ( $₫)$}

Department of Developmental Psychology,

Behavioural Science Institute, Radboud University Nijmegen,

P.O. Box 9104, 6500 HE, Nijmegen, The Netherlands

\section{H. J. A. van Bakel}

Department of Psychology and Health, University of Tilburg, Tilburg, The Netherlands
Externalizing behavior problems - including aggressive, destructive, and delinquent behavior - represent the most common type of mental health problems in children. Longitudinal studies have shown that the stability of externalizing problems is relatively high from preschool age into adolescence (Moffit, Caspi, Dickson, Silva, \& Stanton, 1996; Smith, Calkins, Keane, Anastopoulos, \& Shelton, 2004). Moreover, early externalizing problems are predictive of other forms of psychopathology and often interfere with the child's personal, social and academic development (Campbell, 1995, 2002; Moffitt, 1993). Although developmental psychopathologists now generally assume such problems to have their roots in children's early developmental histories, early identification of children at serious risk of developing such pathology is hampered by a lack of insight into the determinants leading to later maladaptive outcomes (Tremblay, 2006).

Although various theoretical models of the development of externalizing problems in the very first years of life (Campbell, Shaw, Gilliom, 2000; Moffitt, 1993, Greenberg, 1999; Sameroff \& Chandler, 1975) differ in the emphasis they place on the role of certain etiological factors, they agree in the assumption that multiple factors from various domains additively and interactively contribute to the emergence and maintenance of externalizing problems. Taken together, four domains of factors have been proposed to contribute to their development: (a) parent-child interaction and parent-child attachment, (b) child characteristics (e.g., temperament and cognitive abilities), (c) parental characteristics (e.g., personality), and (d) contextual characteristics (e.g., socioeconomic status, partner support, and stressful life events).

To date, very few studies - all focusing on high-risk samples - have longitudinally examined the joint contribution of the various key factors to the onset of externalizing problems in the very first years of life (Aguilar, Sroufe, Egeland, \& 
Carlson, 2000; Erickson, Sroufe, \& Egeland, 1985; LyonsRuth, Alpern, \& Repacholi, 1993; Shaw, Owens, Vondra, Keenan, \& Winslow, 1996). Ours is the first study to assess predictors hypothesized to be the most important from all of the aforementioned domains both in infancy (i.e., at age 15 months) and in toddlerhood (i.e., at age 28 months) to predict the emergence of later externalizing behavior problems (i.e., at age 5 years) in a non high-risk community sample. All of the abovementioned earlier studies of the multiple determinants of externalizing behavior used samples characterized by one or more risk factors. The sample studied by Shaw et al. (1996) included only low-SES families. Aguilar et al. (2000) and Erickson et al. (1985) studied low-SES samples as well, but these were also characterized by high degrees of life stress and a large proportion of single-parent families. And the low-SES sample studied by Lyons-Ruth et al. (1993) was characterized by such additional risk factors as a relatively high incidence of a history of maternal psychiatric hospitalization, single parenthood, and child maltreatment. It remains to be seen whether similar results will also be found in studies with community samples. That is mainly because earlier research has shown that the predictive power of risk factors may increase in the presence of other risk factors (Farrington, 1995). Consequently, it is possible that factors that predict externalizing problems in samples with one or more risk factors fail to do so in samples with lower levels of risk, such as the present sample. In light of this, studying the early predictors of externalizing problems in a community sample constitutes an important extension of the existing research evidence collected in high-risk samples.

The criteria on which we based our selection of the various predictors and our hypotheses regarding their joint contribution to the development of externalizing problems - led by various interrelated theoretical models - are described per domain in the following paragraphs.

Parent-child interaction and parent-child attachment

From a transactional perspective (Sameroff \& Chandler, 1975), externalizing problems are assumed to emerge and to stabilize or change in children's continuous interactions with their immediate environment, particularly in the interactions with their primary caregivers. Repeated observations of parental and child behaviors during parent-child interactions are thus indispensable to gain more insight into the early development of externalizing behavior problems. Multiple dimensions of parental behavior in parent-child interaction have been found to be associated with behavior problems in children at various ages. A lack of positive parenting behaviors, such as the expression of sensitivity, warmth, involvement, acceptance, and positive guidance, was reported to be related to externalizing problems in preschoolers
(Brophy \& Dunn, 2002; Côté, Vaillancourt, LeBlanc, Nagin, \& Tremblay, 2006; Gardner, 1987; Pettit, Bates, \& Dodge, 1997). In addition, high levels of negative parental control such as harsh discipline, intrusiveness, negativity, and hostility also proved associated with externalizing problems (Belsky, Woodworth, \& Crnic, 1996; Rubin, Burgess, Dwyer, \& Hastings, 2003; Campbell, Pierce, Moore, \& Marakovitz, 1996). Based on the above evidence, we expected both a lack of positive parenting behaviors and negative parent-child interactions to predict externalizing behavior problems at age 5 .

Another frequently mentioned risk factor and closely related to the quality of parent-child interaction, is the quality of attachment between infant and caregiver. By the end of the infant's first year, four main patterns of infant-parent attachment - one secure and three insecure - can be distinguished that have been found to reflect the history of the caregiver's responses to the child's attachment behaviors (Ainsworth, Blehar, Waters, \& Wall, 1978; Main \& Solomon, 1986, 1990). Ainsworth and colleagues (1978) originally proposed three "organized" patterns of attachment. Presumably as a result of a history of caregiver sensitive responsiveness to their signals and needs, securely attached (B) infants use the caregiver as a secure base from which to explore the environment. Avoidant (A) infants are characterized by a tendency to minimize their attachment behaviors while under stress in the presence of the caregiver, probably resulting from earlier experiences with a caregiver who tended to reject or ignore the child's expression of attachment behaviors. Infants with a resistant attachment (C), featuring both clinging and angry behaviors towards the caregiver when under stress, are presumed to maximize the expression of attachment behavior as an adaptation to their caregiver's inconsistent responsiveness. Main and Solomon (1990) later added a fourth disorganized (D) pattern typified by seemingly contradictory attachment behaviors that is thought to reflect the breakdown or absence of a strategy for the infant to use the caregiver as a secure base in times of stress (Main \& Solomon, 1990). Disorganized attachment is thought to ensue from extremely unpredictable or frightening behavior on the part of a maltreating and/or traumatized parent (cf. Lyons-Ruth \& Jacobvitz, 1999).

With regard to the predictive value of attachment security versus insecurity for the later occurrence of externalizing problems, the empirical evidence is rather inconsistent. Although attachment insecurity was found to be associated with externalizing problems in high-risk samples as well as in community samples in studies that did not include the disorganized attachment classification (Erickson et al., 1985; Fagot \& Kavanagh, 1990; Munson, McMahon, \& Spieker, 2001; Shaw et al., 1996), other studies did not report such a relationship (Bates, Maslin, \& Frankel, 1985; Goldberg, Corter, Lojkasek \& Minde, 1990). 
However, in contrast to the other insecure attachment categories, disorganized attachment has consistently been found to be related to the later development of externalizing problems (for reviews, see Lyons-Ruth and Jacobvitz, 1999, and Van IJzendoorn, Schuengel, and BakermansKranenburg, 1999; also see Lyons-Ruth et al., 1993; Vondra, Shaw, Swearingen, Cohen, \& Owens, 2001).

In view of the above, we expected infant attachment insecurity and particularly attachment disorganization to be related to elevated levels of externalizing behavior at age 5 . Considering that attachment patterns have been found to reflect the history of parent-child interactions, we expected the association between the early parent-child interaction and later externalizing problems to be at least partially mediated by the quality of the infant-parent attachment.

\section{Child characteristics}

Several child characteristics can prompt the development of externalizing behavior, both directly and indirectly by affecting the quality of parent-child interactions. A considerable body of research has shown associations between externalizing problems and child temperamental characteristics with a crucial role for negative emotionality denoting negative mood, irritability, and high-intensity reactions like anger (for a review, see Sanson, Hemphill, \& Smart, 2004). In contrast, temperamental inhibition and fear/shyness may act as a protective factor as these characteristics have been demonstrated to be negatively associated with later externalizing problems (Lacourse, Nagin, Vitaro, Côté, Arsenault, \& Tremblay, 2006; Sanson, Oberklaid, Prior, Amos, \& Smart, 1996; Schwartz, Snidman, \& Kagan, 1996). Nevertheless, the relationship between child temperament and externalizing behavior is not always clear or direct. Etiological models of externalizing behavior increasingly propose that children with temperamental difficulties are more vulnerable to negative rearing influences than children without such difficulties (Belsky, 1997; Moffitt, 1993). Several recent studies have substantiated this latter assumption (Bates, Pettit, Dodge, \& Ridge, 1998; Belsky, Hsieh, \& Crnic, 1998; Hemphill \& Sanson, 2001; Lacourse et al., 2006; Leve, Kim, $\&$ Pears, 2005). In line with these findings, we anticipated high levels of child negativity and low levels of fearfulness in infancy and toddlerhood, particularly in interaction with parenting, to predict the development of externalizing problems.

Another contributory child characteristic is low cognitive or linguistic ability (Burt, Hay, Pawlby, Harold, \& Sharp, 2004; Dekker, Koot, Van der Ende, \& Verhulst, 2002; Moffitt, 1993). Therefore, we hypothesized that child cognitive ability at 15 months would be negatively related to the occurrence of externalizing problems at age 5 years.
Boys and girls have been found equally likely to exhibit externalizing behavior problems up until the age of about four years. By school entry, however, boys tend to exhibit up to 10 times the rate of externalizing problems for girls (Côté, et al, 2006; Mesman, Bongers, \& Koot, 2001; Rubin et al., 2003). Accordingly, at age 5 we expected the boys in our sample to score higher on externalizing behavior than the girls.

\section{Parental characteristics}

Little research has focused on parental personality as a potential predictor of externalizing problems in children. The available studies only focused on aspects of parental psychopathology like antisocial personality (Shaw, Vondra, Hommerding, Keenan, \& Dunn, 1994) or maternal depression (Cummings \& Davies, 1994; Shaw, Gilliom, Ingoldsby, \& Nagin, 2003). Less attention has been paid to the effects of more or less adaptive parental characteristics, which is why we included parental ego-resiliency as a potential predictor of externalizing problems. Block and Block (1980) defined ego-resiliency as a "resourceful adaptation to changing circumstances," "flexible invocation of the available repertoire of problem-solving strategies," and "the ability to maintain integrated performance while under stress" (p. 48). As such, ego-resilient individuals should be particularly wellequipped to cope with the often stressful task of parenting. And - as outlined before - higher quality parenting is hypothesized to predict lower levels of externalizing behavior in children. In the 15-month assessment (Van Bakel \& RiksenWalraven, 2002a), parental ego-resiliency was found to be related to the infants' socioemotional development, partially via the quality of the parent-infant interaction. Based on the above and in line with the 15-month findings, we expected higher levels of parental ego-resiliency to predict lower levels of externalizing behavior in the children at age 5, and we expected this relation to be mediated by lower quality parent-child interactions.

\section{Contextual characteristics}

Besides parental and child attributes, specific characteristics of the social and economic context in which the parent-child interaction is embedded may also contribute to the development of externalizing problems (Belsky, 1984; Greenberg, Speltz, \& DeKlyen, 1993). We included three characteristics of the child-rearing context that earlier studies have shown to be associated with externalizing problems: (1) high incidence of stressful life events (Aguilar et al., 2000), (2) a lack of partner support (Jouriles, Murphy, Farris, Smith, Richters, \& Waters, 1991; Shaw et al., 1996), and (3) low socioeconomic status (SES; Côté, et al, 2006; Shaw et al., 1996). It needs to be stressed, though, that in previous research the 
effects of sociodemographic factors like SES proved modest compared to the effects of parental or child risk factors (for a review, see Loeber and Dishion, 1983; also see Shaw et al., 1996). Nevertheless, based on earlier findings, we expected stressful life events, partner support, and SES to contribute to the development of externalizing behavior problems.

In sum, the aim of the present study was to predict the occurrence of externalizing behavior problems in a sample of 5-year-old children on the basis of various parental, child, dyadic, and contextual factors assessed at 15 and 28 months and at age 5 . We expected the following specific factors to independently or interactively contribute to the development of externalizing problems: (a) a low quality of parent-child interaction at 15 and 28 months; (b) disorganized parentinfant attachment; (c) child temperament (i.e., high anger proneness and low fearfulness) at both 15 and 28 months and particularly in interaction with low quality parenting; (d) low levels of child cognitive ability at 15 months; (e) low parental ego-resiliency; (f) high incidence of stressful life events between 15 months and 5 years; (g) lack of partner support; and (h) low SES. Furthermore, the contribution of parental ego-resiliency to child externalizing behavior was expected to be mediated by the quality of parent-child interaction, and the contribution of the early parent-child interaction by the quality of infant-parent attachment.

\section{Method}

\section{Participants}

The original 15-month sample $(M=15.1 ; S D=0.25)$ consisted of 129 healthy children (67 boys, 62 girls) and their primary caregivers. The children were recruited on the basis of the records from health-care centers in the Dutch city of Nijmegen. During nine consecutive months, all families $(n=639)$ with a 15 -month-old baby from various socioeconomic backgrounds were sent a recruitment letter with a brief description of the research procedures and an invitation to participate in this study that aimed to "gain more insight into children's development in the first years of life". If they met the two specified eligibility criteria (i.e., sufficient fluency in Dutch and child without serious health problems) and were interested in participation, they were requested to return a response card. Of the 174 families who responded, 129 parentchild dyads (the maximum attainable given the time and resources available for the project) were randomly selected for the study. Of the infants, 73 were first-borns and 56 had one or more older siblings. The sample included 123 two-parent families and six single-parent families. In three families, the father was the primary caregiver and in the remainder of the families this was the mother. The percentages of single parents and fathers acting as primary caregivers are representative of families in the Netherlands with children in this age group. The primary caregivers were between the ages of 22 and 47 years at the time of recruitment. The level of education for the primary caregivers was indicated on a seven-point scale from low (elementary school) to high (college degree or more) with a mean of $4.95(S D=1.77)$; the category equivalent of 5 is high school degree. Of the 12915-month-olds, 114 children (61 boys, 53 girls) participated in the second wave of measurements at age 28 months $(M=28.3 ; S D=0.30)$ and 116 ( 62 boys, 54 girls) in the third assessment at age 5 years $(M=63.6$ months; $S D=1.16)$. At this third assessment, there were 107 two-parent families, nine single-parent families, and again three families with the father as the primary caregiver. ${ }^{1}$

To determine whether there was selective drop-out or not, the 116 families participating in the 5-year assessment were compared to the 13 families that did not take part. Independent $t$-tests for all the major 15-month study variables revealed a significant difference for parental ego-resiliency only, $t(126)=2.08, p<.05$, with a tendency for primary caregivers with lower levels of ego-resiliency to drop out.

\section{Procedure}

The 15-month data were available from an earlier study focusing on the determinants of parenting and infant development (Van Bakel \& Riksen-Walraven, 2002a). The 15-month assessment involved data collection during a single home visit and a single visit of the primary caregiver and infant to the research center. During the home visit, the primary caregiver completed a Q-sort and a set of questionnaires assessing child temperament, parental ego-resiliency, partner support, and additional background information. Next, the parentchild interaction was videotaped during the performance of four instructional tasks lasting three to four minutes each. At the subsequent assessment at the research center, the child's cognitive ability was assessed and the quality of the infantparent attachment with an abbreviated version of the Strange Situation (Ainsworth et al., 1978). For a more detailed description of the 15-month data collection, see Van Bakel \& Riksen-Walraven (2002a, 2002b)

The 28-month assessment was conducted during a single home visit. The primary caregiver was interviewed about stressful life events since the first assessment and asked to complete a questionnaire to assess child temperament. The parent-child interaction was videotaped during

\footnotetext{
${ }^{1}$ Virtually the same results were obtained when the three families in which fathers were the primary caregivers were excluded.
} 
four instructional tasks comparable to those performed at 15 months.

At the age-5 assessment, the primary caregiver was interviewed at home about stressful life events since the previous assessment and asked to complete a questionnaire to assess child behavior problems. The child's teacher completed a questionnaire to assess any behavior problems and asked to return this by mail, which was done by all but one teacher.

Instruments and measures

\section{Quality of parent-child interaction (at 15 and 28 months)}

The videotaped parent-child interaction episodes were rated using five 7-point scales (Erickson et al., 1985) to assess the quality of parental interactive behavior: (1) supportive presence or the provision of emotional support; (2) respect for the child's autonomy or nonintrusiveness; (3) effective structure and limit setting; (4) quality of instructions; and (5) hostility. Subsequently, child interactive behavior was rated on four 7point scales (Erickson, et al., 1985): (I) negativity or anger, dislike, and hostility towards the parent; (II) avoidance of interaction with the parent; (III) compliance to suggestions and directions given by the parent; and (IV) positive affect expressed towards the parent. Each interaction episode at 15 months was rated independently by two trained observers and each interaction episode at 28 months by four independent observers. Based on 25 cases (19\%) for the 15-month assessment and 20 cases (18\%) for the 28 -month assessment, the interrater reliabilities expressed as adjusted kappas were all above 0.83 . Evidence for the validity of the scales has been provided in various studies (see Van Bakel \& RiksenWalraven, 2000a, for a review).

To obtain robust dyadic measures for parent-child interaction, the ratings of parental and child interactive behavior were factor analyzed together, for the 15- and 28-month assessment separately, using varimax rotation. Scree plots of eigenvalues indicated the emergence of two clear and comparable factors at both ages. The two factors explained $68 \%$ of the variance in parent-child interaction at 15 months, and $71 \%$ of the variance at 28 months. The first factor, labeled effective guidance, was marked by high loadings on the following parent-child interaction variables (factor loadings for 15 and 28 months within parenthesis): effective structure and limit setting $(.89 ; .95)$, high quality of instructions $(.62 ; .76)$, and supportive presence $(.79 ; .48)$ on the part of the parents; and compliance $(.53 ; .84)$ and low avoidance $(-.52 ;-.65)$ on the part of the child. The second factor, labeled negative interaction, was characterized by high loadings on the following variables (factor loadings for 15 and 28 months within parenthesis): parental hostility $(.74 ; .85)$; low respect
$(-.63 ;-.78)$; child negativity $(.85 ; .67)$; and an increasing lack of positive affect in both partners as evident from low parental supportive presence $(-.48 ;-.77)$ and low child positive affect $(-.35 ;-.54)$.

\section{Quality of parent-child attachment (at 15 months)}

An abbreviated version of the Strange Situation Procedure (Ainsworth et al., 1978), i.e., including one as opposed to two separation-reunion situations, was used to assess the quality of infant-parent attachment. A similarly abbreviated version of the Strange Situation has been found to be valid for the assessment of attachment quality both within normal (Lewis, Feiring, McGuffog, \& Jaskir, 1984; Waters, Wippman, \& Sroufe, 1979) and within clinical samples (Willemsen-Swinkels, Bakermans-Kranenburg, Buitelaar, Van IJzendoorn, \& Van Engeland, 2000). Two trained coders (the second author and D.C van den Boom from the University of Amsterdam) rated the videotaped separation-reunion episodes and classified the infants as Secure (B), Avoidant (A), Resistant (C), or Disorganized/ disoriented (D) consistent with the directions provided by Ainsworth et al. (1978) and by Main \& Solomon (1990). Intercoder reliability on 20 cases $(16 \%)$ was adequate, with 95\% agreement on the main classifications.

\section{Child temperament (at 15 and 28 months)}

Child temperament was evaluated using the Toddler Behavior Assessment Questionnaire (TBAQ; Goldsmith, 1994) The TBAQ comprises 111 items, organized in five 7-point scales. For the present study, two scales were used that have earlier been found associated with externalizing problems, i.e., Anger proneness (28 items, Cronbach's alpha .89 and .88 for 15 and 28 months, respectively) and Social fear (19 items, Cronbach's alpha .77 and .84 for 15 and 28 months, respectively).

\section{Cognitive ability (at 15 months)}

A Dutch version of the Bayley (1969) Mental Scale of Infant Development (Van der Meulen \& Smrkovsky, 1983) was used to assess the child's level of cognitive functioning at 15 months, expressed in the standardized Mental Developmental Index (MDI, $M=100 ; S D=15$ ).

\section{Parental ego-resiliency (at 15 months)}

Primary caregivers rated their own ego-resiliency using a Dutch translation of the California Adult Q-set (CAQ; Block, 1961, 1978) The CAQ consists of 100 descriptive statements that sample a broad domain of personal and interpersonal 
characteristics and functioning. The primary caregivers were asked to sort each statement into one of nine possible categories ranging from "least characteristic" to "most characteristic" in terms of salience for themselves. An ego-resiliency score was then attained by correlating the Q-sort description for each parent with the criterion profile provided by experts for a prototypically ego-resilient person (see Block, 1991). The ego-resiliency scores could range from +1.00 (very ego-resilient) to -1.00 (very ego-brittle).

\section{Stressful life events (at 28 months and 5 years)}

A semi-structured interview was used to obtain information regarding stressful life events occurring between the three assessments. The questions/items were derived from Saranson, Johnson, and Siegel's (1978) Life Experiences Survey and Coddington's (1972) Life Events Scale for Children. Both measures have sound psychometric properties and have been widely used in international research (Abela, 2001; Johnston, 1996). Stressful events that were likely to have a negative impact on the child's development were selected for inclusion (e.g., loss of a loved one, serious physical or mental illness on the part of a parent or the child, divorce). All items required a 'yes' or 'no' response. The total number of stressful life events between 15 and 28 months and 28 months and age 5 were taken together to constitute the stressful life event scores between 15 months and age 5 .

\section{Partner support (at 15 months)}

A subscale of a Dutch questionnaire to assess family problems (VGP; Koot, 1997) was used to assess the support the primary caregiver received from the partner. The subscale comprises five statements gauging partner support during child rearing, such as "My partner supports me in my role as a parent" and "My partner and I agree about child rearing." Cronbach's alpha was 0.82 . Single parents were also asked to complete the questionnaire when they were still in contact with the other parent or were living with a new partner. Otherwise, they were assigned a minimum score. Evidence supporting the validity of the subscale has been reported in various studies (Van Bakel \& Riksen-Walraven, 2002a; Van Zeijl et al., 2006).

\section{Socioeconomic status (SES at 15 months)}

SES scores were assigned on the basis of the level of education (along a 7-point scale) and level of occupation (along a 6-point scale) for both parents. SES scores based on education and occupation of both parents have frequently been used in other studies (e.g., Shaw et al., 1996). The levels of education and occupation for the two parents were first stan- dardized and then summed to derive a single SES score. For single parents, the level of education and occupation for the primary caregiver were summed to compute the SES score (cf. Shaw et al., 1996).

\section{Externalizing problems as rated by parents and teachers (5 years)}

To assess externalizing problems at age 5 , the parents completed the Dutch version of the Child Behavior Checklist for ages 4-18 (CBCL/4-18; Achenbach, 1991a; Verhulst, Van der Ende, \& Koot, 1996). The Aggressive behavior subscale (20 items) and the Delinquent behavior subscale (13 items) from the CBCL/4-18 were summed (combined $\alpha=.86$ ) to determine the externalizing score for the child at 5 years. Teachers completed the teacher version of the CBCL (TRF, Achenbach 1991b); the externalizing score was based on the scores for the subscales Aggressive behavior (25 items) and Delinquent behavior (9 items) which were summed (combined $\alpha=.94$ ) to derive an externalizing score for each child.

\section{Results}

Results are presented in two sections. In the first section we report the results of preliminary analyses, i.e., the distributions of the various predictor and outcome variables as well as their intercorrelations, and the parental and teacher ratings of the children's externalizing behaviors are compared and related to each other. The second section reports the main results of the study, namely the prediction of externalizing behavior at age 5 from the various predictors at earlier ages. First, hierarchical regression analysis is conducted to estimate the unique and interactive contributions of the multiple predictors to the variance in Externalizing scores at age 5. Next, the hypothesized mediated pathways are tested. Finally, path analysis using AMOS 5.0 (Arbuckle, 2003) is applied to test the complete longitudinal model comprising all the direct, moderated, and mediated pathways of influence between the predictors at the various ages and age 5 externalizing behavior.

Preliminary analyses

Table 1 presents the means and standard deviations for the study variables as well as their intercorrelations. The distribution of children across attachment categories $(64 \% \mathrm{~B}$, $14 \% \mathrm{~A}, 8 \% \mathrm{C}$, and $14 \% \mathrm{D}$ ) did not differ from the distribution reported by Van IJzendoorn et al. (1999) for "normal", i.e., middle-class, non-clinical groups in North America. The scores for child cognitive ability were normally distributed, 


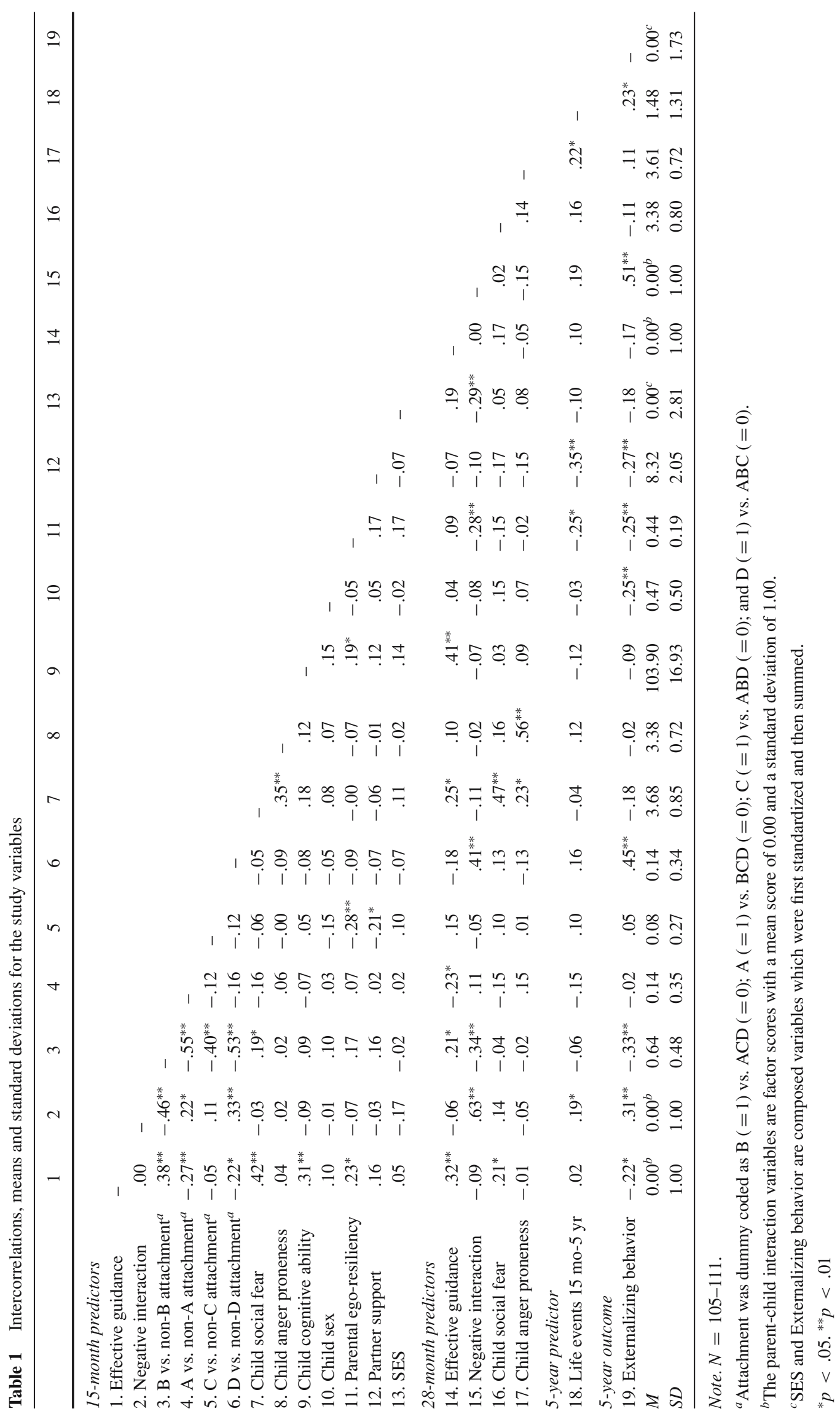


with a mean score close to the population mean of $M=100$. The distribution of the scores for ego-resiliency was in line with the findings of earlier studies and the distribution of scores for partner support was mildly to moderately skewed to the left but showed sufficient variation. Table 1 also shows significant stability for the two parent-child interaction measures as well as for child social fear and anger proneness from 15 to 28 months. For the predictor variables, no differences were found between boys and girls.

The mean score on the Externalizing scale was 9.97 $(S D=6.35 ; N=111)$ for the CBCL/4-18 with $22 \%$ $(n=24)$ of the children scoring in the clinical range ( $T$ score of $\geq 63$; Achenbach, 1991a). For the TRF, the mean score was $7.50(S D=9.10 ; N=111)$ with $16 \%(n=18)$ of the children scoring in the clinical range $(T \geq 63$; Achenbach, 1991b). Both the CBCL and TRF Externalizing scores were significantly higher than those reported for 5-year-olds in the Dutch norm population for the CBCL/4$18(M=8.23, S D=6.37$; Verhulst et al., 1996) and the TRF $(M=4.99, S D=6.58$; Verhulst, Van der Ende, $\&$ Koot, 1997), $t(185)=2.26, p<.05$ for the CBCL/4-18, and $t(185)=2.51, p<.05$ for the TRF. A paired-samples $t$-test showed parents to report significantly more externalizing behaviors than school teachers, $t(110)=3.24, p<.01$. The correlation between the CBCL and TRF scores was $.51, p<.001$. To obtain a robust measure of externalizing behavior, a composite Total Externalizing score was computed by first standardizing and then summing the children's Externalizing scores on the CBCL and TRF. For sex differences on this measure, a $t$-test revealed a significantly higher score for boys on Total Externalizing $\left(M_{\text {boys }}=0.41\right.$, $S D=1.93 ; M_{\text {girls }}=-0.44, S D=1.35, t(109)=2.70$, $p<.01)$.
Predicting age 5 externalizing scores

\section{Hierarchical regression analysis}

To examine the unique and interactive contributions of the predictors to the variance in Externalizing scores at age 5, hierarchical multiple regression analysis was conducted with Total Externalizing as the dependent variable and the predictors at the different ages as the independent variables. The predictors were entered in the first block. In the second block, the interaction terms hypothesized in the introduction to predict Externalizing scores were entered, i.e., child temperament $(2$ measures $) \times$ parent-child interaction $(2$ measures) at both 15 and 28 months, and child cognitive development $\times$ parent-child interaction ( 2 measures) at 15 months. The interaction terms were computed according to the procedure recommended by Aiken and West (1991). To limit the number of interaction terms in the regression analysis, only those interaction terms that significantly predicted externalizing behavior at age 5 when examined in isolation were included in the regression analysis (see also Leve et al., 2005), i.e., Effective guidance $\times$ Anger proneness at 28 months and Negative interaction $\times$ Anger proneness at 28 months. Table 2 presents the results for the final model.

The overall model proved significant and explained $47.6 \%$ of the variance in the Total Externalizing scores. In the first block, D versus non-D attachment at 15 months explained a significant $22 \%$ of the variance in the Total Externalizing scores at age 5. Negative interactions at 28 months explained an additional $11 \%$ of the variance, child sex accounted for another $4 \%$, just like anger proneness at 28 months, and partner support at 15 months contributed another $3 \%$ to the regression equation. In the second block,
Table 2 Hierarchical regression results for predicting age 5 externalizing scores (Total Model)

\begin{tabular}{|c|c|c|c|c|c|}
\hline \multirow[b]{2}{*}{ Block } & & \multicolumn{4}{|c|}{ Hierarchical regression results } \\
\hline & & $B$ & $S E B$ & $\beta$ & $\Delta \mathrm{R}^{2}(\%)$ \\
\hline \multirow[t]{5}{*}{1} & D versus non-D attachment ${ }^{a}$ & 1.88 & 0.42 & $.36^{* *}$ & 22.2 \\
\hline & Negative interaction 28 months & 0.65 & 0.15 & $.35^{* *}$ & 10.7 \\
\hline & Sex $(\text { male })^{b}$ & 0.61 & 0.26 & $.18^{*}$ & 4.3 \\
\hline & Anger proneness 28 months & 0.47 & 0.18 & $.20^{* *}$ & $4.4^{c}$ \\
\hline & Partner support & -0.14 & 0.06 & $-.17^{*}$ & 2.6 \\
\hline \multirow[t]{3}{*}{2} & Interaction terms & & & & \\
\hline & Effective guidance $\times$ Anger proneness 28 months & -0.33 & 0.14 & $-.19^{* *}$ & 3.3 \\
\hline & & & \multicolumn{3}{|c|}{$\begin{array}{c}R^{2} \text { final model }=47.6 \% \\
F(6,94) \text { final model }=14.21^{* *}\end{array}$} \\
\hline
\end{tabular}

${ }^{a} \mathrm{D}$ vs. non-D coded as $D=1$ and non- $D=0$.

${ }^{b}$ Sex was coded as 0 (girls) or 1 (boys).

${ }^{c}$ Although anger proneness was not significantly correlated with externalizing behavior, it had a significant Beta weight. This effect seems due to a suppressor variable. As recommended by Tabachnick \& Fidell (1989), predictors were systematically deleted from the regression equation to identify which variable is the suppressor, indicating that $\mathrm{D}$ versus non- $\mathrm{D}$ attachment acted as the suppressor variable.

${ }^{*} p<.05 .{ }^{* *} p<.01$. 
Fig. 1 Child externalizing behavior scores in relation to effective guidance for children high and low on anger-proneness

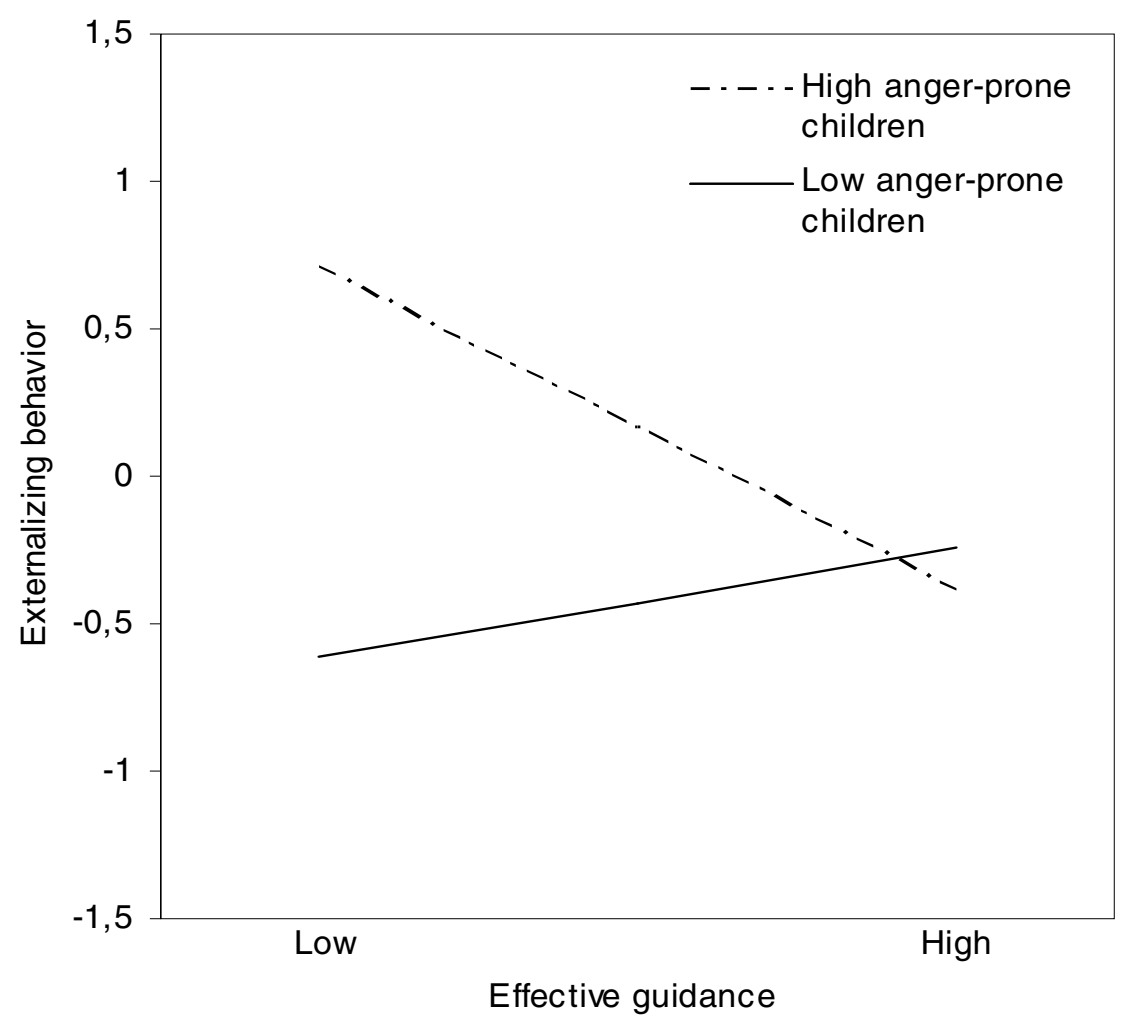

Effective guidance $\times$ Anger proneness at 28 months explained another $3 \%$ of the variance in Total Externalizing scores at age 5 .

To examine the nature of the interaction effect of effective guidance and anger proneness at 28 months on externalizing behavior at age 5 , the relationship between effective guidance and externalizing behavior was determined for children with high ( $1 S D$ above the mean) and low (1SD below the mean) levels of anger proneness, following the procedures of Aiken and West (1991). The regression lines for high and low anger prone children are plotted in Fig. 1. The simple slope of effective guidance was significant at high levels of anger proneness $(B=-.55, t(107)=-2.56, p<.05)$, but not at low levels of anger proneness $(B=.19, t(107)=1.01$, $n s$.). Thus, a lack of effective guidance was associated with more externalizing behavior for highly anger prone children but not for low anger prone children.

\section{Mediational analyses}

Next, the hypothesized mediated pathways between the predictors and age 5 externalizing behavior were tested using regression analysis, according to the procedure outlined by Baron and Kenny (1986). According to this procedure, three conditions must hold in order to establish mediation: (a) the predictor is significantly associated with the outcome, (b) the predictor is significantly associated with the mediator, and (c) the mediator is significantly associated with the outcome.
If these conditions hold in the predicted direction, mediation is proven when the effect of the predictor on the outcome is shown to decrease when the mediator is also entered as a predictor in the regression equation.

First, we tested whether D versus non-D attachment mediated the effect of the parent-child interaction (two measures) at 15 months on age 5 externalizing behavior. For both hypothesized pathways, the three abovementioned conditions for establishing mediation were met (see Table 1 for correlations). Furthermore, the effect of effective guidance at 15 months on externalizing behavior $(\beta=-.22, p<.05)$ dropped to a nonsignificant level $(\beta=-.13, n s)$ when $\mathrm{D}$ versus non-D attachment was controlled for (Sobel test: $z=-2.11, p<.05)$, showing that $\mathrm{D}$ versus non-D attachment completely mediated the effect of effective guidance at 15 months on externalizing behavior. The effect of negative interactions at 15 months on externalizing behavior $(\beta=-.31, p<.001)$ decreased but remained significant when $\mathrm{D}$ versus non-D attachment was controlled for $(\beta=-.18, p<.05)$; Sobel's test showed the decrease to be significant $(z=2.77, p<.01)$. These findings indicate that negative interactions at 15 months are associated with age 5 externalizing behavior both directly and via $\mathrm{D}$ versus non-D attachment.

Next, we tested whether the effect of parental egoresiliency on child externalizing behavior was mediated by the quality of the parent-child interaction (two measures) at 15 and 28 months. As evident from Table 1, the three 
Fig. 2 Final path model summarizing the pattern of direct, moderated, and mediated relations between predictors at 15 and 28 months and age 5 externalizing behavior. Values given are standardized path coefficients. ${ }^{*} p<.05$. ${ }^{* *} p<.01$

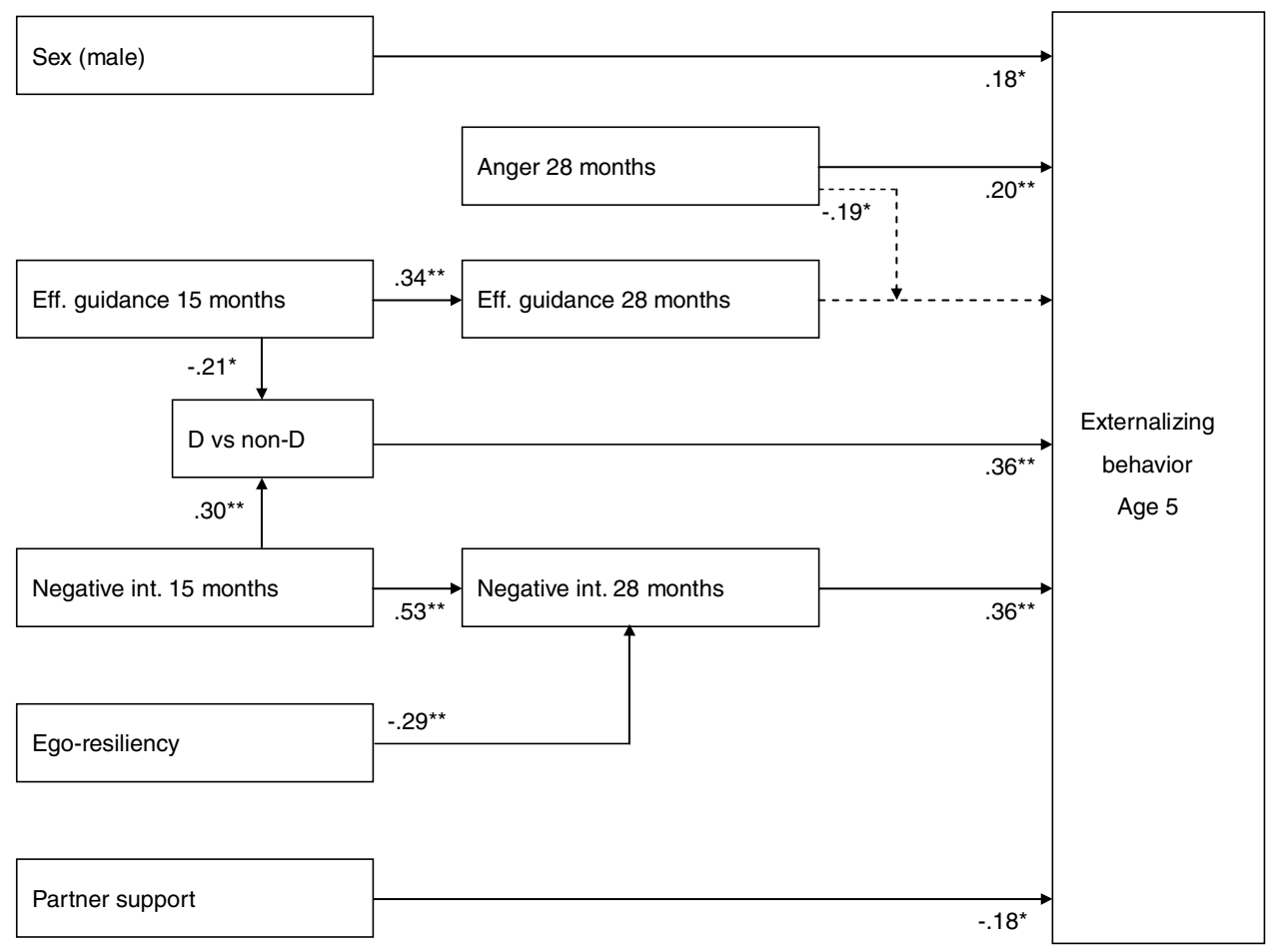

conditions for establishing mediation only held for one of the four possible pathways, namely for the pathway mediated by negative interactions at 28 months. For this pathway, multiple regression showed the effect of parental ego-resiliency on externalizing behavior $(\beta=-.25, p<.01)$ to decrease (Sobel test: $z=-2.63, p<.01$ ) to a nonsignificant level $(\beta=-.12, n s)$ when negative interactions at 28 months was controlled for. These results indicate that the effect of parental ego-resiliency on children's externalizing behavior was completely mediated by negative parent-child interactions at 28 months.

\section{Path analysis}

Finally, path analysis using AMOS 5.0 (Arbuckle, 2003) was applied to test the complete longitudinal model for predicting age 5 externalizing behavior including: (1) all the direct and moderated relations between the predictors and age 5 externalizing behavior found in the regression analysis; (2) the three significant mediated pathways resulting from the mediational analyses; and (3) the longitudinal relations between the 15- and 28-month assessments of the two parent-child interaction factors (i.e., effective guidance and negative parent-child interactions). A good model fit is indicated by a nonsignificant $\chi^{2}$ statistic, a Bentler comparative fit index (CFI) of .95 or above, and root mean square error of approximation (RMSEA) of .05 or below. The analysis of the initial model yielded a significant fit $\left(\chi^{2}=21.86\right.$, $d f=23, p=.53$, CFI $=1.00$, RMSEA $=.00)$, indicating that the model fits the data well. ${ }^{2}$ The final model, including the standardized path coefficients, is depicted in Fig. 2.

\section{Discussion}

The present study is one of the first attempts, and the first with a community sample, to include the theoretically most important parental, child, dyadic, and contextual characteristics, longitudinally assessed in both infancy and toddlerhood, in the prediction of externalizing behavior problems at age 5. Data were gathered using multiple sources (parents and teachers) and multiple methods, including questionnaires, standardized tests and extensive observations of the parent-child interaction. Predictors from all four domains were found to be associated with children's externalizing behavior at age 5, which is in accordance with the results of earlier studies using high-risk samples (Aguilar et al., 2000; Erickson et al., 1985; Lyons-Ruth et al., 1993; Shaw et al., 1996). The longitudinal model that emerged from our analyses provides more insight into the pattern of direct,

2 The final model was also tested separately with the parent-rated (CBCL) and the teacher-rated externalizing scores as outcomes. For both the parent-rated and the teacher-rated externalizing scores, the model fitted the data well $\left(\chi^{2}=22.69, d f=23, p=.48\right.$, $\mathrm{CFI}=1.00$, RMSEA $=0.00$ for parent-rated externalizing behavior, and $\chi^{2}=24.37, d f=23, p=.38, \mathrm{CFI}=.99, \mathrm{RMSEA}=0.02$ for teacher-rated externalizing behavior). 
moderated and mediated influences that work together to shape the development of externalizing behavior problems across the first five years of life.

As emphasized in the introduction, the present study was conducted on a non high-risk sample, in contrast to the above prior longitudinal studies that were all conducted on highrisk samples. After recruitment, when the children were 15 months of age, the sample appeared to be representative of the Dutch population of families with young children and therefore was not considered as a high-risk sample (see Van Bakel \& Riksen-Walraven, 2002a). At the 5-year assessment, the selective drop-out of families with relatively low ego-resilient parents seemed to make the risk status of the remaining sample even lower. In this light, our finding that the children had higher CBCL and TRF externalizing scores than the relevant normative Dutch samples is puzzling. It may be that the level of externalizing behavior problems has increased over the last few years; unfortunately, no recent normative data are available. An alternative explanation may be that in middle-class communities, families with concerns about their children's development are more likely to volunteer for research studies. Because relevant information is not available for the present sample, this remains an issue for further study.

The only hypothesized predictors that were not associated with later externalizing behavior were SES and child temperament and cognitive ability at 15 months. The lack of association between SES and externalizing behavior is in line with earlier studies that also reported parental and child characteristics to be more consistently associated with externalizing behavior than contextual characteristics (Shaw et al., 1996). Restriction of range in SES scores in our sample is not a likely explanation for the null findings given that the sample seems to be fairly representative of the Dutch population of families with children in the same age range, as indicated above. Yet, it may be that the variation of SES in the Netherlands is less than in other countries, such as the USA. Further research is recommended to examine how well the model that our analyses generated applies in community samples from other countries or for ethnically diverse samples of parents and children. The present nonsignificant relations between infant temperament and cognitive ability on the one hand and externalizing behavior on the other are in line with the results of two other recent longitudinal studies, both using high-risk samples (Aguilar et al., 2000; Brennan, Hall, Bor, Majman, \& Williams, 2003), that also failed to find an association between early temperamental and neuropsychological risks on the one hand and persistent aggressive behavior on the other. Given that - as argued in the introduction - the predictive power of risk factors may be higher in high-risk samples than in lower-risk samples, it is not surprising that variables that failed to predict externalizing behavior in high-risk samples also failed to predict such problems in a lower-risk sample like ours. With regard to the predictive power of risk factors in relation to sample risk status, it should be noticed that comparing the predictive power of risk factors in studies differing in sample risk status is not the most elegant way to address this question. A more direct way to test whether risk factors interact with sample risk status is by testing for interactive effects in a sample with a greater range of risk (see, for example, Lacourse et al., 2006).

Although temperament assessed in infancy did not interact with the parent-child interaction in the prediction of externalizing behavior, temperament assessed in toddlerhood did. More specifically, a parent-child interaction characterized by a lack of effective guidance in toddlerhood predicted externalizing behavior only in highly anger-prone toddlers but not in less anger-prone toddlers. This finding seems to support Belsky's (1997) differential susceptibility hypothesis that not all children are similarly affected by the same rearing experience. It should be kept in mind, however, that our effective guidance factor not only includes parental behavior, but child behavior as well. With the same reserve, our findings appear to also be in line with the results of studies that showed child negative emotionality to interact with parenting in predicting externalizing problems (Belsky et al., 1998; Leve et al., 2005). Rather than an association with negative parent-child interactions and hence in contrast to earlier reports, our findings showed temperament to interact with a different dimension of the parent-child interaction, namely a lack of effective guidance. This is not to say that negative parent-child interactions as such carried no weight in the prediction of externalizing problems in the present study. Quite the contrary, the factor proved to be one of the most powerful predictors of externalizing behavior problems in the present study and this was true for all the children in our sample and not just for a subsample of temperamentally difficult children.

Our results on the interaction between temperament and parenting in the development of externalizing problems extend those of earlier studies by showing that a specific temperament by parenting interaction may work particularly in a specific developmental phase. That the interaction between anger proneness and effective guidance proved to predict externalizing problems particularly for toddlers makes sense when interpreted from a developmental psychopathology perspective: establishing autonomy and learning to comply with social rules and expectations are major developmental tasks for toddlers that challenge the parents' ability to provide effective guidance by imposing structure and setting limits while at the same time remaining emotionally supportive of the child. As a result of the child's striving for autonomy, the second year is marked by parent-toddler conflicts. Toddlers that are prone to show angry behaviors in such discord situations are particularly in need of effective guidance in order to prevent their lack of emotional and 
behavioral self-control to further escalate and evolve into externalizing behavior problems.

Our finding that $\mathrm{D}$ attachment was among the strongest predictors of externalizing behavior at age 5 supports the results of previous research (Lyons-Ruth et al., 1993; Munson et al., 2001; Shaw et al., 1996; Vondra et al., 2001). Disorganized attachment has been found to reflect a history of disturbed parent-child interaction on the one hand and to predict later externalizing problems on the other (cf. LyonsRuth \& Jacobvitz, 1999). The results of our path analysis have shed more light on the nature of the contributions of the parent-child interaction and parent-child attachment to the development of externalizing behavior problems. First of all, our path analysis showed D attachment to mediate the relations between the two aspects of parent-child interaction (i.e., effective guidance and negative interaction) at 15 months and externalizing behavior at age 5. In addition, the results showed negative parent-child interactions at 28 months to contribute significantly to later externalizing problems beyond $\mathrm{D}$ attachment at 15 months. These findings are in line with earlier findings by Erickson et al. (1985) and support Greenberg's (1999) model that considers parent-child interaction and parent-child attachment as two different domains that contribute independently to a child's development but that also reciprocally influence one another.

The results of this study may have clinical and policy implications. Many studies have shown that children born in disadvantaged environments are at risk for developing externalizing problems later in life. The present study showed that, also for children living in presumably lower-risk families, certain characteristics in infancy and toddlerhood indicate an increased risk of externalizing problems at preschool age. It should be kept in mind, however, that our sample may have been more at risk than originally thought, because a relatively large proportion of children turned out to have externalizing behavior scores above the subclinical cutoff. An important practical implication of our findings is that one of the most powerful predictors identified in the present study, i.e., negative parent-child interactions, is relatively easy to observe already in infancy and proves to be highly stable, which makes it an interesting candidate for inclusion in early community mental health screening procedures. And the specific interaction of the other parent-child interaction factor (i.e., effective guidance) with temperamental anger proneness in toddlerhood in predicting later externalizing problems also suggests that paying more attention to early parent-child interactions may be useful in early detection of children at risk and in preventive intervention programs for parents in community mental health care. But more research is needed, of course, to further explore these possible applications.

It is important to also point out limitations of the present study. First, although it is a strong point that data were col- lected using multiple methods and multiple sources, parental report was the sole source of information regarding four different predictors of externalizing problems, namely infant temperament, parental ego-resiliency, partner support, and stressful life events. Thus, response bias may have partially accounted for the results. What speaks against this, however, is that the four predictors were mostly uncorrelated with each other (see Table 1). Only stressful life events was significantly correlated with two other predictors (i.e., ego-resiliency and partner support), which may explain why negative life events did not independently contribute to the explanation of later externalizing problems beyond the other two predictors. Another limitation is that the present study focused on the role of children's experiences with their primary caregivers in the development of externalizing problems, which leaves questions regarding the possible effects of the children's experiences with other caregivers and with their peers, for example in child-care centers (cf. Gevers Deynoot-Schaub \& Riksen-Walraven, 2006). A third limitation of the study is that we did not have additional information about earlier externalizing behavior and about characteristics of the children and families prior to our first 15-month assessment at our disposal. Future research that includes observations earlier in infancy may further improve our understanding of the mechanisms involved in the early development of externalizing problems. A fourth limitation lies in the relatively small sample size. The sample was small by epidemiological standards, particularly with regard to evaluating mediator and moderator effects. And as a fifth and final limitation of the present study it should be mentioned that we based our assessments of the quality of infant-parent attachment on an abbreviated version of the Strange Situation that includes one as opposed to two separations from the parent. Despite the evidence supporting the validity of the abbreviated procedure (see Method section), it is possible that we have underestimated the number of $\mathrm{D}$ children given that in the regular Strange Situation Procedure children may be classified as disorganized based on their reunion behavior after the second separation. Anyhow, the present study shows that D attachment, even when assessed with the abbreviated Strange Situation, was a powerful predictor of later externalizing behavior problems.

In sum, the longitudinal model our analyses generated provides more insight into the complex interplay among parental, child, dyadic and contextual characteristics that together shape the development of externalizing behavior from age 15 months onwards. Future research should reveal whether the predictive power of the model can be improved, for instance by including earlier measurements and by taking into account the children's early experiences with the other parent and with their caregivers and peers in child-care facilities. 
Acknowledgement This study was supported by a grant from the Netherlands Organization for Scientific Research (NWO, Grant 42520-702 to the second author). We thank Toon Cillessen for his helpful statistical advice.

\section{References}

Abela, J. R. Z. (2001). The Hopelessness Theory of Depression: A Test of the Diathesis-Stress and Causal Mediation Components in Third and Seventh Grade Children. Journal of Abnormal Child Psychology, 29, 241-254.

Achenbach, T. M. (1991a). Manual for the Child Behavior Checklist/418 and 1991 Profile. Burlington, VT: University of Vermont, Department of Psychiatry.

Achenbach, T. M. (1991b). Manual for the Teacher's Report Form and 1991 Profile. Burlington, VT: University of Vermont, Department of Psychiatry.

Aguilar, B., Sroufe, L. A., Egeland, B., \& Carlson, E. (2000). Distinguishing the early-onset/persistent and adolescence-onset antisocial behaviour types: From birth to 16 years. Development and Psychopathology, 12, 109-132.

Aiken, L. S., \& West, S. G. (1991). Multiple regression: Testing and interpreting interactions. Thousands Oaks, CA: Sage.

Ainsworth, M. D. S., Blehar, M. C., Waters, E., \& Wall, S. (1978). Patterns of attachment: A psychological study of the Strange Situation. Hillsdale, NJ: Erlbaum.

Arbuckle, J. (2003). Amos users' guide, version 5.0. Chicago: Smallwaters.

Baron, R. M., \& Kenny, D. A. (1986). The Moderator-Mediator Variable Distinction in Social Psychological Research: Conceptual, Strategic, and Statistical Considerations. Journal of Personality and Social Psychology, 51, 1173-1182.

Bates, J. E., Maslin, C. A., \& Frankel, K. A. (1985). Attachment security, mother-child interaction, and temperament as predictors of behavior-problem ratings at age three years. Monographs of the Society for Research in Child Development, 50, 167-193.

Bates, J. E., Pettit, G. S., Dodge, K. A., \& Ridge, B. (1998). Interaction of temperamental resistance to control and restrictive parenting in the development of externalizing behavior. Developmental Psychology, 34, 982-995.

Bayley, N. (1969). Bayley Scales of Infant Development. New York: Psychological Corporation.

Belsky, J. (1984). The determinants of parenting: A process model. Child Development, 55, 83-96.

Belsky, J. (1997). Variation in susceptibility to environmental influences: An evolutionary argument. Psychological Inquiry, 8, 182186.

Belsky, J., Hsieh, K., Crnic, K. (1998). Mothering, fathering, and infant negativity as antecedents of boys' externalizing problems and inhibition at age 3 years: Differential susceptibility to rearing experience? Development and Psychopathology, 10, 301-319.

Belsky, J., Woodworth, S., \& Crnic, K. (1996). Troubled family interaction during toddlerhood. Development and Psychopathology, 8 , 477-495.

Block, J. (1961/1978). The Q-sort method in personality assessment and psychiatric research. Springfield, IL: C. C. Thomas; reprinted 1978, Palo Alto, CA: Consulting Psychology Press.

Block, J. (1991). Prototypes for the Californian Adult Q-set. Berkeley: Department of Psychology, University of California.

Block, J. H., \& Block, J. (1980). The role of ego-control and egoresiliency in the organisation of behaviour. In W. A. Collins (Ed.), The Minnesota Symposia on Child Psychology (Vol. 13, pp. 39101). Hillsdale, NJ: Erlbaum.
Brennan, P. A., Hall, J., Bor, W., Majman, J. M., \& Williams, G. (2003). Integrating biological and social processes in relation to early-onset persistent aggression in boys and girls. Developmental Psychology, 39, 309-323.

Brophy, M., \& Dunn, J. (2002). What did mummy say? Dyadic interactions between young "hard to manage" children and their mothers. Journal of Abnormal Child Psychology, 30, 103-112.

Burt, K. B., Hay, D. F., Pawlby, S., Harold, G., \& Sharp, D. (2004). The prediction of disruptive behavior disorders in an urban community sample: The contribution of person-centered analyses. Journal of Child Psychology and Psychiatry, 45, 1159-1170.

Campbell, S. B. (1995). Behavior problems in preschool children: A review of recent research. Journal of Child Psychology and Psychiatry, 36, 113-149.

Campbell, S. B. (2002). Behavior problems in preschool children: Clinical and developmental issues. New York: The Guilford Press.

Campbell, S. B., Pierce, E. W., Moore, G., \& Marakovitz, S. (1996). Boys' externalizing problems at elementary school age: Pathways from early behavior problems, maternal control, and family stress. Development and Psychopathology, 8, 701-719.

Campbell, S. B., Shaw, D. S., \& Gilliom, M. (2000). Early externalizing behavior problems: Toddlers and preschoolers at risk for later maladjustment. Development and Psychopathology, 12, 467488.

Coddington, R. (1972). The significance of life events as etiological factors in the diseases of children. I. A survey of professional workers. Journal of Psychosomatic Research, 16, 7-18.

Côté, S. M., Vaillancourt, T., LeBlanc, J. C., Nagin, D. S., \& Tremblay, R. E. (2006). The development of physical aggression from toddlerhood to pre-adolescence: A nation wide longitudinal study of Canadian children. Journal of Abnormal Child Psychology, 34, 71-85.

Cummings, E. M., \& Davies, P. T. (1994). Maternal depression and child development. Journal of Child Psychology and Psychiatry and Allied Disciplines, 35, 73-112.

Dekker, M. C., Koot, H. M., Van Der Ende, J., \& Verhulst F. C. (2002). Emotional and behavioral problems in children and adolescents with and without intellectual disability. Journal of Child Psychology and Psychiatry, 43, 1087-1098.

Erickson, M. F., Sroufe, L. A., \& Egeland, B. (1985). The relationship between quality of attachment and behavior problems in preschool in a high-risk sample. Monographs of the Society for Research in Child Development, 50, 147-166.

Fagot, B. I., \& Kavanagh, K. (1990). The prediction of antisocial behavior from avoidant attachment classification. Child Development, 61, 864-873.

Farrington, D. P. (1995). The development of offending antisocial behaviour from childhood: Key findings from the Cambridge study in delinquent development. Journal of Child Psychology and Psychiatry, 36, 1-36.

Gardner, F. (1987). Positive interaction between mothers and conductproblem children: Is there training for harmony as well as fighting? Journal of Abnormal Child Psychology, 15, 283-293.

Gevers Deynoot-Schaub, M. J. J. M., \& Riksen-Walraven, J. M. A. (2006). Peer interaction in child care centres at 15 and 23 months: Stability and links with children's socio-emotional adjustment. Infant Behavior and Development, 29, 276-288.

Goldberg, S., Corter, C., Lojkasek, M., \& Minde, K. (1990) Prediction of behaviour problems in 4-year-olds born prematurely. Development and Psychopathology, 2, 15-30.

Goldsmith, H. H. (1994). The toddler behavior assessment questionnaire: Preliminary manual. Unpublished manuscript, University of Oregon.

Greenberg, M. T. (1999). Attachment and psychopathology in childhood. In J. Cassidy \& P. R. Shaver (Eds.), Handbook of 
attachment: Theory, research, and clinical applications (pp. 469-496.

Greenberg, M. T., Speltz, M. L., \& DeKlyen, M. (1993). The role of attachment in the early development of disruptive behavior problems. Development and Psychopathology, 5, 191213.

Hemphill, S., \& Sanson, A. (2001). Matching parenting to child temperament. Family Matters, 59, 42-47.

Johnston, C. (1996). Parent characteristics and parent-child interactions in families of nonproblem children and ADHD children with higher and lower levels of oppositional-defiant behavior. Journal of Abnormal Child Psychology, 24, 85-104.

Jouriles, E. N., Murphy, C. M., Farris, A. M., Smith, D. A., Richters, \& Waters, E. (1991). Marital adjustment, parental disagreements about child rearing, and behavior problems in boys: Increasing the specificity of the marital assessment. Child Development, 62, 1424-1433.

Koot, H. (1997). Vragenlijst voor Gezinsproblemen [Family Problems Questionnaire]. Rotterdam: Erasmus University.

Lacourse, E., Nagin, D. S., Vitaro, F., Côté, S. M., Arsenault, L., \& Tremblay, R.E. (2006). Prediction of early-onset deviant peer group affiliation: A 12-year longitudinal study. Archives of General Psychiatry, 63, 562-569.

Leve, L. D., Kim, H. K., \& Pears, K. C. (2005). Childhood temperament and family environment as predictors of internalizing and externalizing trajectories from ages 5 to 17. Journal of Abnormal Child Psychology, 33, 505-520.

Lewis, M., Feiring, C., McGuffog, C., \& Jaskir, J. (1984). Predicting psychopathology in six-year-olds from early social relations. Child Development, 55, 123-136.

Loeber, R., \& Dishion, T. (1983). Early predictors of male delinquency: A review. Psychological Bulletin, 94, 68-99.

Lyons-Ruth, K., Alpern, L., \& Repacholi, B. (1993). Disorganized infant attachment classification and maternal psychosocial problems as predictors of hostile-aggressive behavior in the preschool classroom. Child Development, 64, 572-585.

Lyons-Ruth, K., \& Jacobvitz, D. (1999). Attachment disorganization: Unresolved loss, relational violence, and lapses in behavioral and attentional strategies. In J. Cassidy, \& P. R. Shaver (Eds.), Handbook of attachment: Theory, research, and clinical applications (pp. 520-554). New York, NY, US: Guilford Press.

Main, M., \& Solomon, J. (1986). Discovery of a new, insecuredisorganized-disoriented attachment pattern. In T. B. Brazelton \& M. W. Yogman (Eds.), Affective development in infancy (pp. 95-124). Norwood, NJ: Ablex.

Main, M., \& Solomon, J. (1990). Procedures for identifying infants as disorganized/disoriented during the Ainsworth Strange Situation. In M. T. Greenberg, D. Cicchetti, \& E. M. Cummings (Eds.), Attachment in the preschool years: Theory, research, and intervention (pp. 121-160). Chicago: University of Chicago Press.

Mesman, J., Bongers, I. L., \& Koot, H. M. (2001). Preschool developmental pathways to preadolescent internalizing and externalizing problems. Journal of Child Psychology and Psychiatry, 42, 679689.

Moffitt, T. E. (1993). Adolescence-limited and life-course-persistent antisocial behavior: A developmental taxonomy. Psychological Review, 100, 674-701.

Moffitt, T. E., Caspi, A., Dickson, N., Silva, P., \& Stanton, W. (1996). Childhood-onset versus adolescent-onset antisocial conduct problems in males: Natural history from ages 3 to 18 years. Development and Psychopathology, 8, 399-424.

Munson, J. A., McMahon, R. J., \& Spieker, S. J. (2001). Structure and variability in the developmental trajectory of children's externalizing problems: Impact of infant attachment, maternal depressive symptomatology, and child sex. Development and Psychopathology, 13, 277-296.
Pettit, G. S., Bates, J. E., \& Dodge, K. A. (1997). Supportive parenting, ecological context, and children's adjustment: A seven-year longitudinal study. Child Development, 68, 908-923.

Rubin, K. H., Burgess, K. B., Dwyer, K. M., \& Hastings, P. D. (2003). Predicting preschoolers' externalizing behavior from toddler temperament, conflict, and maternal negativity. Developmental Psychology, 39, 164-176.

Rubin, K. H., Hastings, P., Stewart, S., Henderson, H., \& Chen, X. (1997). The consistency and concomitants of inhibition. Child Development, 68, 467-483.

Sameroff, A. J., \& Chandler, M. J. (1975). Reproductive risk and the continuum of caretaking casualty. In F. D. Horowitz, M. Hetherington, S. Scarr-Salapatek, \& G. Siegal (Eds.), Review of child development research (Vol. 4, pp. 187-244). Chicago: University of Chicago Press.

Sanson, A., Hemphill, A. A., \& Smart, D. (2004). Connections between temperament and social development: A review. Social Development, 13, 142-170.

Sanson, A., Oberklaid, F., Prior, M., Amos, D., \& Smart, D. (1996). Risk factors for 11-12 year olds' internalising and externalising behaviour problems. Paper presented at the biennial meeting of the International society for the study of behavioural development, Quebec City, Quebec, Canada, August.

Saranson, I. G., Johnson, J. H., \& Siegel, J. M. (1978). Assessing the impact of life changes: development of the life experiences survey. Journal of Consulting and Clinical Psychology, 46, 932-946.

Schwartz, C. E., Snidman, N., \& Kagan, J. (1996). Early childhood temperament as a determinant of externalising behaviour in adolescence. Development and Psychopathology, 8, 527-537.

Shaw, D. S., Gilliom, M., Ingoldsby, E. M., \& Nagin, D. S. (2003). Trajectories leading to school-age conduct problems. Developmental Psychology, 39, 189-200.

Shaw, D. S., Owens, E. B., Vondra, J. I., Keenan, K., \& Winslow, E. B. (1996). Early risk factors and pathways in the development of early disruptive behavior problems. Development and Psychopathology, 8, 679-699.

Shaw, D. S., Vondra, J. I., Hommerding, K., Keenan, K., \& Dunn, M. (1994). Chronic family adversity and early child behaviour problems: A longitudinal study of low- income families. Journal of Child Psychology and Psychiatry, 35, 1109-1122.

Smith, C. L., Calkins, S. D., Keane, S. P., Anastopoulos, A. D., \& Shelton, T. L. (2004). Predicting stability and change in toddler behavior problems: Contributions of maternal behavior and child gender. Developmental Psychology, 40, 29-42.

Tremblay, R. E. (2006). Prevention of youthe violence: Why not start at the beginning? Journal of Abnormal Child Psychology, 34, 481487.

Van Bakel, H. J. A., \& Riksen-Walraven, J. M. A. (2002a). Parenting and development of one-year-olds: Links with parental, contextual, and child characteristics. Child Development, 73, 256-273.

Van Bakel, H. J. A., \& Riksen-Walraven, J. M. A. (2002b). Quality of infant-parent attachment as reflected in infant interactive behaviour during instructional tasks. Journal of Child Psychology and Psychiatry, 43, 387-394.

Van Der Meulen, B. F., \& Smrkovsky, M. (1983). BOS 2-30 Bayley Ontwikkelingsschalen [Bayley Scales of Infant Development]. Lisse, The Netherlands: Swets \& Zeitlinger.

Van IJzendoorn, M. H., Schuengel, C., \& Bakermans-Kranenburg, M. J. (1999). Disorganized attachment in early childhood: Metaanalysis of precursors, concomitants, and sequelae. Development and Psychopathology, 11, 225-249.

Van Zeijl, J., Mesman, J., Stolk, M. N., Alink, L. R. A., Van IJzendoorn, M. H., Bakermans-Kranenburg, M. J., et al. (2006). Terrible ones? Assessment of externalizing behaviors in infancy with the Child Behavior Checklist. Journal of Child Psychology and Psychiatry, 47, 801-810. 
Verhulst, F. C., Van Der Ende, J., \& Koot, H. M. (1996). Handleiding voor de CBCL/4-18 [Manual for the CBCL/4-18]. Rotterdam: Afdeling Kinder- en Jeugdpsychiatrie, Sophia Kinderziekenhuis/Academisch Ziekenhuis Rotterdam, Erasmus Universiteit Rotterdam.

Verhulst, F. C., Van Der Ende, J., \& Koot, H. M. (1997). Handleiding voor de Teacher's Report Form (TRF) [Manual for the TRF]. Rotterdam: Afdeling Kinder- en Jeugdpsychiatrie, Sophia Kinderziekenhuis/Academisch Ziekenhuis Rotterdam, Erasmus Universiteit Rotterdam.

Vondra, J. I., Shaw, D. S., Swearingen, L., Cohen, M., \& Owens, E. B. (2001). Attachment stability and emotional and behavioral reg- ulation from infancy to preschool age. Development and Psychopathology, 13, 13-33.

Waters, E., Wippman, J., \& Sroufe, L. A. (1979). Attachment, positive affect, and competence in the peer group: Two studies in construct validation. Child Development, 50, 821-829.

Willemsen-Swinkels, S. H. N., Bakermans-Kranenburg, M. J., Buitelaar, J. K., Van IJzendoorn, M. H., \& Van Engeland, H. (2000). Insecure and disorganised attachment in children with a pervasive developmental disorder: relationship with social interaction and heart rate. Journal of Child Psychology and Psychiatry, $41,759-767$. 